\title{
Cavernoma of the conus medullaris mimicking transverse myelitis
}

Srikant Balasubramaniam ${ }^{1}$, MCh, Amit $\underline{\text { Mahore }}^{2}$, MCh

ABSTRACT We present an interesting case of conus medullaris cavernoma that was initially treated as transverse myelitis. Haemorrhagic lumbar puncture led us to perform magnetic resonance (MR) imaging, which showed the presence of a cavernous angioma at the D12-L1 level. The total excision of the lesion was followed by dramatic improvement. We suggest that MR imaging be performed early in all suspected cases of transverse myelitis so that emergency surgical intervention can be offered before the development of permanent neurological deficits.

Keywords: cavernoma of conus medullaris, cavernous angioma of the cord, intramedullary cavernoma, transverse myelitis

Singapore Med J 2013; 54(2): e24-e27

\section{INTRODUCTION}

Cavernous angiomas (or cavernomas) are vascular malformations of the central nervous system (CNS), representing $5 \%-12 \%$ of spinal vascular abnormalities. ${ }^{(1)}$ Spinal cavernous malformations occur most commonly in the vertebrae and may extend into the extradural spinal canal. ${ }^{(2)}$ The most uncommon locations in the spinal cord are the lumbar spine and conus medullaris, with each constituting $3 \%$ of all intramedullary cavernomas. ${ }^{(1)}$ It usually presents with worsening of the neurological status due to haemorrhage within the cord, ${ }^{(1,2)}$ which may simulate transverse myelitis. Diagnostic imaging is mandatory and conclusive in such cases. Early surgical intervention aimed at total excision of the offending lesion is indicated in symptomatic cases to prevent the development of permanent neurological deficits.

\section{CASE REPORT}

A 45-year-old Indian man presented with sudden onset of weakness in his lower limbs, which was associated with urinary retention and constipation for the past six hours. He had low back pain, low grade fever and neck stiffness. Examination revealed grade 0/5 power and flaccidity in both the lower limbs. Deep tendon reflexes were absent, while plantar response was equivocal. He had hypoaesthesia below the D12 level. Although anal tone was normal, anal and bulbocavernosus reflexes were absent. The patient was admitted to the emergency medical department with a diagnosis of transverse myelitis and started on high dose methylprednisolone. Lumbar puncture examination was performed and the cerebrospinal fluid (CSF) report is presented in Table I. The absence of lymphocytic predominance, and raised red blood cell and sugar levels in the CSF indicated bleeding, for which magnetic resonance (MR) imaging of the spine was indicated. MR imaging showed a well-defined lesion at the D12-L1 level, which was hyperintense on T1-weighted
Table I. Results of the patient's CSF examination.

\begin{tabular}{lll}
\hline Characteristic & Observed & Normal \\
\hline $\begin{array}{l}\text { Physical } \\
\text { Colour }\end{array}$ & Red & $\begin{array}{l}\text { Colourless } \\
\text { Clear }\end{array}$ \\
$\begin{array}{l}\text { Turbidity } \\
\text { Biochemical }(\mathbf{m g} / \mathbf{d L})\end{array}$ & \\
$\quad$ Glucose & 65 & $40-85$ \\
Protein & 152 & $15-45$ \\
Cells & & \\
RBC (cells $/ \mu \mathrm{L})$ & 4,503 & 0 \\
WBC (cells $/ \mu \mathrm{L})$ & $260(20 \%$ lymphocytes $)$ & $0-5$ \\
CSF oligoclonal bands & Absent & Absent \\
\hline
\end{tabular}

RBC: red blood cell; WBC: white blood cell; CSF: cerebrospinal fluid

imaging with post-contrast enhancement and hypointense on T2-weighted imaging (Figs. 1 \& 2).

In view of the patient's acute onset of symptoms, the decision to operate was taken. A wide laminectomy at the D12-L2 level was performed with the patient under general anaesthesia and in a prone position. A midline durotomy was performed at the same level, following which tacking sutures were taken. The patient's CSF was bloodstained. The lesion, visualised on the dorsal surface, was greyish-blue in colour and soft to firm in consistency. After separating the overlying arachnoid membrane, a well-defined plane of gliotic tissue between the lesion and the normal cord was appreciated. The lesion was totally excised en bloc, with minimal bipolar coagulation and no damage to the surrounding cord or nerve rootlets. Watertight dural closure was performed after haemostasis was achieved. The patient was extubated on the table, and no added neurological deficits were detected. Intraoperative neurophysiological monitoring was not performed, as the tumour had a very good dissecting plane, with no adhesions to the cord or surrounding nerve rootlets.

Histopathology revealed sinusoidal vascular channels with simple endothelial lining and no intervening neural parenchyma.

${ }^{1}$ Department of Neurosurgery, BYL Nair Hospital, ${ }^{2}$ Department of Neurosurgery, King Edward Memorial Hospital, Mumbai, India

Correspondence: Dr Srikant Balasubramaniam, Assistant Professor, Department of Neurosurgery, BYL Nair Hospital, Dr AL Nair Road, Mumbai Central, Mumbai 400008, India. srikantbala@yahoo.com 


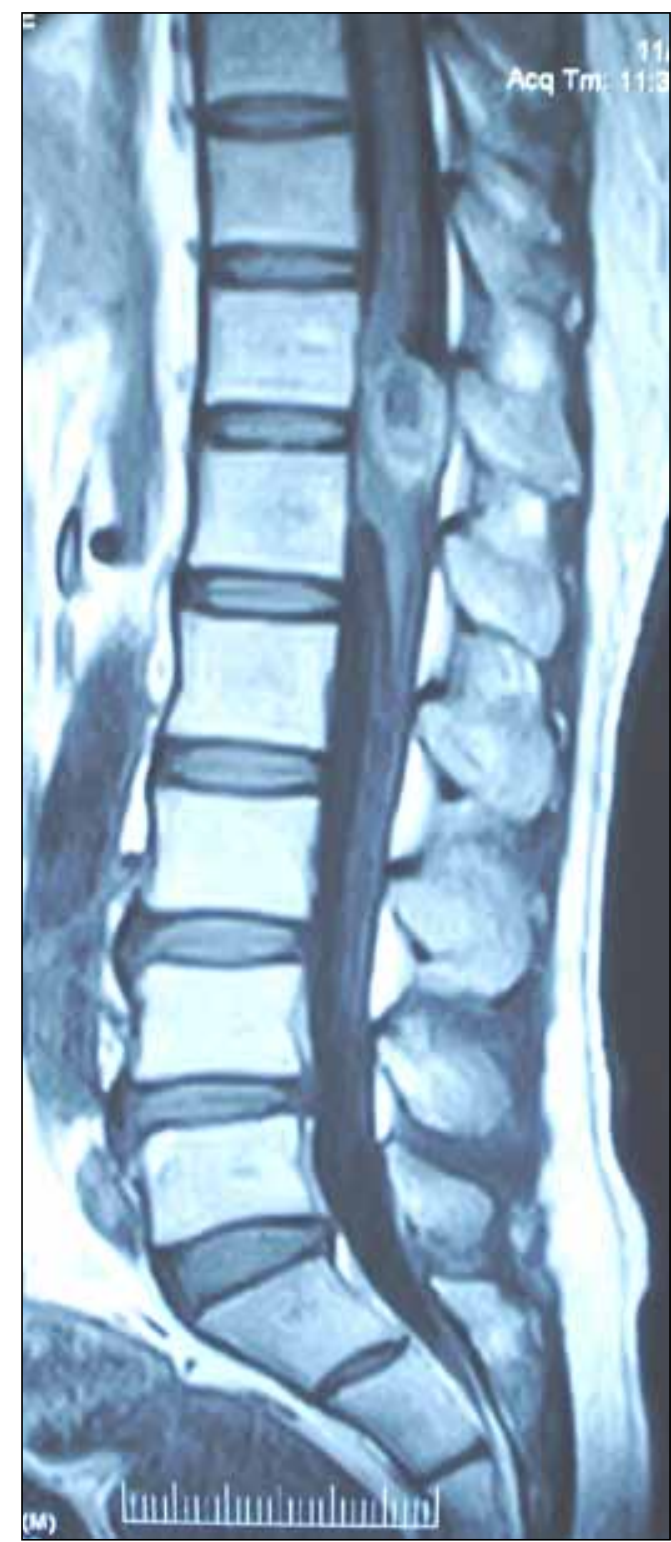

Fig. 1 T1-W sagittal MR image shows a hyperintense lesion at the D12-L1 level, which caused cord compression in the patient.

The adventitial layer was thin, with an absent muscle layer. There was evidence of perilesional gliosis and haemosiderin deposition, which was suggestive of old haemorrhage in the lesion. The pathological impression was that of a cavernoma (Fig. 3).

Neurorehabilitation programme in the form of limb physiotherapy and mobilisation exercises was initiated six hours postoperatively. A stabilisation programme ${ }^{(3)}$ that focused on neuromuscular control of the thoracolumbar spine was employed. The patient's initial physiotherapy began with segmental breathing exercises and active assisted range of motion. An isometric exercise programme (inclusive of static back extensor, abdominal and glutei exercises) was incorporated during the initial postoperative period. The patient showed remarkable improvement from Day 3 post surgery. He was discharged on Day 5 and his sutures were removed on Day 10.

At discharge, the patient and his caregivers were educated on the safe level of functional mobility of the brace. Following discharge, the patient was on follow-up at the physiotherapy

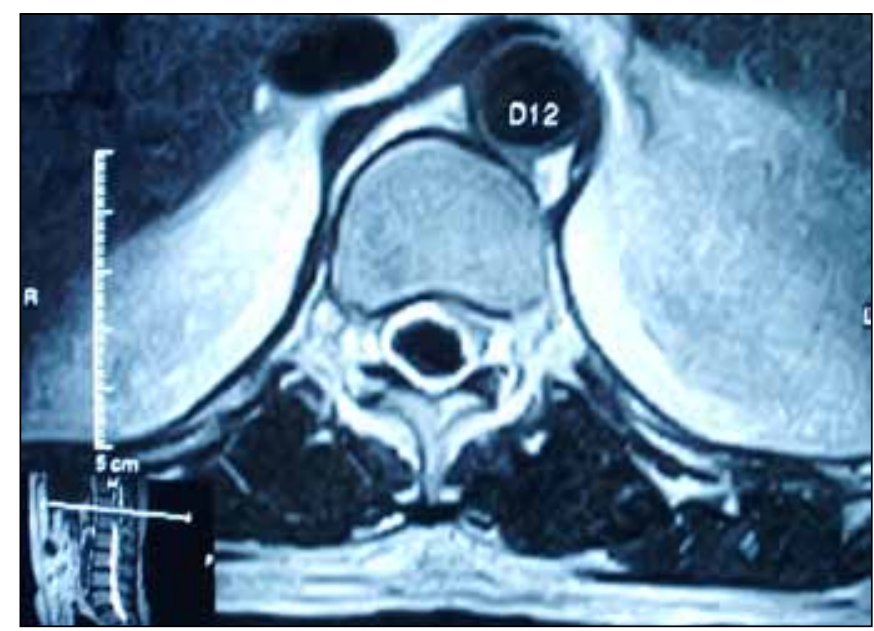

Fig. 2 T2-W axial MR image shows a well-defined hypointense lesion at the level of the conus medullaris.

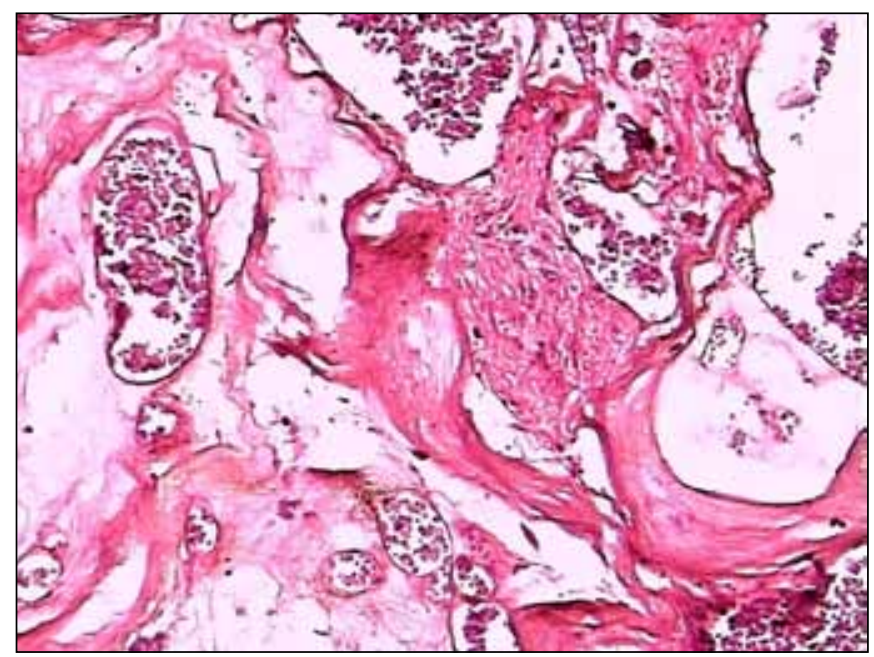

Fig. 3 Photomicrograph shows thin-walled and hyalinised vascular spaces with recent and old haemorrhages in the stroma (Haematoxylin \& eosin, $\times 100)$

outpatient department thrice a week and a supervised home exercise programme. An exercise regime to activate the deep (core) stabilising muscles of the trunk was started in order to develop habitual activation of spinal stability in the patient. Postural correction with the assistance of a mirror to attain correct standing posture as well as progressive balance and gait training sessions were also introduced. When the patient had achieved active control of his movement, he was encouraged to walk independently. The abovementioned graded mobilisation programme was facilitated by a team consisting of a neurosurgeon, neurologist, occupational therapist, physiotherapist and patient counsellor. By the third week post operation, the patient was ambulatory, and at one year, no motor, sensory or autonomic deficits were found in the patient. His anal and bulbocavernosus reflexes had also normalised.

\section{DISCUSSION}

Being rare vascular malformations of the CNS, cavernous angiomas are included in cryptic or angiographically occult CNS vascular malformations. ${ }^{(1)}$ They are most commonly seen in the cerebral hemisphere and brainstem. ${ }^{(2)}$ Most are found in 
Table II. Compilation of the most common causes of cauda equina syndrome. ${ }^{(7)}$

\begin{tabular}{|c|c|}
\hline Type of lesion & Aetiology \\
\hline $\begin{array}{l}\text { Nonneoplastic } \\
\text { compressive }\end{array}$ & $\begin{array}{l}\text { - Herniated lumbosacral disks } \\
\text { - Spinal stenosis } \\
\text { - Epidural abscess } \\
\text { - Spinal subdural/epidural haematoma } \\
\text { - Arteriovenous malformations }\end{array}$ \\
\hline $\begin{array}{l}\text { Neoplastic } \\
\text { compressive }\end{array}$ & $\begin{array}{l}\text { - Schwannoma } \\
\text { - Ependymoma } \\
\text { - Lipoma } \\
\text { - Teratoma } \\
\text { - Secondaries - breast, prostate, kidney, } \\
\text { myeloproliferative }\end{array}$ \\
\hline Noncompressive & $\begin{array}{l}\text { - Ischaemic - anterior spinal artery syndrome } \\
\text { - Inflammatory - Bechterew syndrome } \\
\text { - } \text { Spinal arachnoiditis } \\
\text { - Infective - bacterial, viral } \\
\text { - Iatrogenic-postsurgical after intradiskal therapy } \\
\text { - Post chiropractic } \\
\text { - Post epidural anaesthesia }\end{array}$ \\
\hline
\end{tabular}

the supratentorial cerebral parenchyma (59\%) and 39\% are infratentorial. Only $2 \%$ of cavernomas are located within the spinal cord. (1) Spinal cavernomas represent $5 \%-12 \%$ of all spinal vascular abnormalities, with most of them arising within the vertebral bodies and extending into the extradural spinal space. ${ }^{(1,2)}$ Among the intramedullary cavernomas in a series by Ogilvy et al ${ }^{(4)}$ the cervicomedullary junction, cervical region, thoracic segment, lumbar cord and conus medullaris were involved in $8 \%, 32 \%, 54 \%, 3 \%$ and $3 \%$ of the cases, respectively. In our search for conus medullaris cavernomas, we found a report of three cases of cavernoma of the conus medullaris by Pagni et $\mathrm{al}^{\left({ }^{(5)}\right.}$ and two more reports by Hernandez et $\mathrm{a}^{(1)}$ and Montano et $\mathrm{a}^{(6)}$ detailing one case each.

Spinal angiomas are prone to bleeding, with a reported incidence of $0.5 \%-1 \%$ per year. ${ }^{(1)}$ Ogilvy et al classified the symptoms according to four major clinical patterns: (a) acute episodes of stepwise deterioration with small but repeated haemorrhages, or with thrombosis of the malformed vessels; (b) slow progression due to progressive enlargement of the cavernoma, eventually with thickening of the sinusoid vessels and gradual thrombosis; (c) acute onset with rapid deterioration due to intraparenchymal haemorrhages; and (d) acute onset with gradual decline attributable to altered microcirculation due to intraparenchymal haemorrhage. ${ }^{(4)}$ Our patient belonged to the third category and his acute symptoms were probably caused by the new haemorrhage within or around the lesion.

Cavernous angiomas are angiographically occult. MR imaging is diagnostic and the investigation method of choice. ${ }^{(1,2)}$ On T1- and T2-weighted images, the typical MR characteristics of cavernomas appear as reticulated mixed signal areas, predominantly surrounded by low signal intensity in T2-weighted imaging. Enhancement is modest and cord swelling is occasional. A hyperintense signal may indicate the presence of an old clot or haemosiderin. ${ }^{(2)}$ Lesions that show similar characteristics on imaging include neoplastic lesions like astrocytoma, ependymoma, neurofibroma, inflammatory lesions such as granuloma, and other vascular pathologies such as arteriovenous malformation. In our case, transverse myelitis can be a differential diagnosis of cavernous angioma. Proximal weakness can be explained by the presence of haemorrhage in the cord and fever can be explained by the presence of blood in the CSF. Radiology, blood investigations and CSF analysis can differentiate transverse myelitis from cavernous angioma. Orendacova et al ${ }^{(7)}$ have compiled a list of differential diagnoses of cauda equina syndrome (Table II). However, clinically, we can rule out most of the differential diagnoses mentioned in Table II. The acute presentation of symptoms in our patient excludes slow-growing neoplastic and infective lesions. The absence of radiating or disproportionate pain also rules out extradural compression such as a herniated disc or haematoma. Ischaemic aetiology remains a possibility, but can be ruled out by imaging and CSF analysis.

Total surgical excision under high magnification using microsurgical techniques is the procedure of choice for the management of symptomatic cavernous angioma of the conus medullaris.(2) The absence of neural tissue among the vascular channels allows for complete resection of the lesion with minimal or no neurological deficits. (1) In order to lower the risk of injury to the normal surrounding tissue, dissection must consist of performing myelotomy directly over the bluish discolouration of the lesion, and should be limited to the surrounding haemosiderin-stained gliotic plane.(2) Subtotal removal may lead to the reappearance of symptoms and continued progressive deterioration as a result of bleeding from residual malformation.(2) If the risk of bleeding is lower than the surgical risk, a trial of conservative management is advised. Other available nonsurgical treatment options, like radiotherapy and conservative rehabilitation therapy, may be used in such cases. ${ }^{(1)}$ Asymptomatic cavernomas are best managed conservatively, and the role of surgical intervention in such cases is controversial.(1)

In conclusion, cavernoma of the conus medullaris is a very rare entity that may mimic a variety of pathologies. We propose that suspected cases of transverse myelitis should not be treated presumptively and early MR imaging should be performed to rule out any surgically correctable pathology. Meticulous, complete surgical excision of a symptomatic lesion with microneurosurgical technique should be performed before the development of permanent neurological deficits.

\section{ACKNOWLEDGEMENTS}

The authors would like to acknowledge the following persons: Prof Atul H Goel for his support and encouragement, and Preeti $S$ Dhende for the help rendered in the preparation of the section on neurorehabilitation.

\section{REFERENCES}

1. Hernandez D, Moraleda S, Royo A, et al. Cavernous angioma of the conus medullaris as a cause of paraplegia. Spinal Cord 1999; 37:65-7.

2. Anand S, Puri V, Sinha S, Malhotra V. Intramedullary cavernous 
haemangioma. Neurol India 2001; 49:401-3.

3. Kisner C, Colby LA, eds. Therapeutic exercise: Foundation and Techniques. 5th ed. Philadelphia: F.A. Davis Company, 2007.

4. Ogilvy CS, Louis DN, Ojemann RG. Intramedullary cavernous angiomas of the spinal cord: clinical presentation, pathological features and surgical management. Neurosurgery 1992; 31:219-30.
5. Pagni CA, Canavero S, Forni M. Report of a cavernoma of the cauda equina and review of the literature. Surg Neurol 1990; 33:124-31.

6. Montano N, Signorelli F, Tufo T, et al. Teaching Neurolmages: extralesional bleeding of conus medullaris cavernoma. Neurology 2010; 6:75.

7. Orendacova J, Cizkova D, Kafka J, et al. Cauda equina syndrome. Prog Neurobiol 2001; 64:613-37. 